\title{
PELATIHAN PEMBUATAN E-LEARNING SEBAGAI MEDIA PEMBELAJARAN BAGI SISWA DI SMP NEGERI 29 PALEMBANG
}

\author{
Dewi Sartika'), Husnawati²), Imelda Saluza3), Maya Amelia ${ }^{4}$ ) \\ 2),3)Program Studi Manajemen Informatika Fakultas Ilmu Komputer \\ 1),4)Program Studi Teknik Informatika Fakultas Ilmu Komputer \\ Jalan Jend. Sudirman No. 629 Palembang Kode Pos : 30129 \\ Email : dewi.sartika@uigm.ac.id 1), uthy.51291@gmail.com ${ }^{13}$, imeldasaluza@uigm.ac.id2), \\ realmayamaknyak@yahoo.co.id ${ }^{4)}$
}

\begin{abstract}
ABSTRAK
Perkembangan dibidang teknologi dan ilmu pengetahuan membuat dunia pendidikan harus semakin peka dalam peningkatan kualitas sumber daya yang dimilikinya. Oleh karena itu untuk menyikapi fenomena tersebut perlu adanya tindak lanjut dalam membekali tenaga pengajar dengan berbagai kemampuan agar tidak statis akan tetapi berkembang secara dinamis. Salah satunya yaitu dengan adanya pelatihan pembuatan e-learning sebagai media pembelajaran bagi siswa SMP Negeri 29 Palembang. Kegiatan pelatihan ini menjelaskan tentang e-learning, manfaatnya dalam dunia pendidikan dan penggunaanya sebagai media pembelajaran. Proses kegiatan dilaksanakan selama 1 hari. Tujuan kegiatan ini adalah tenaga pengajar di lingkungan SMP Negeri 29 Palembang memahami manfaat elearning, dalam hal ini khususnya edmodo sebagai media pembelajaran yang lebih atraktif dan menarik dalam usaha peningkatan minat belajar dan pemahaman siswa terhadap materi belajar, serta memudahkan interaksi antara tenaga pengajar dan siswa.
\end{abstract}

Kata Kunci : media pembelajaran, e-learning, edmodo

\section{PENDAHULUAN}

\subsection{Latar belakang}

Ada tiga kata yang harus kita pahami sebelumnya, yaitu Information (informasi), Communication (Komunikasi) dan Technology (Teknologi). Informasi merupakan hasil dari data yang diolah dan menerangkan sesuatu serta berguna bagi yang mengetahuinya. Komunikasi merupakan pengiriman dan penerimaan pesan atau berita antara 2 pihak atau lebih sehingga pesan yang dimaksud dapat dipahami. Teknologi merupakan kemampuan teknik yang berlandaskan pengetahuan ilmu eksakta yang berdasarkan proses teknis. Dengan demikian Information and Communication Technology (ICT) atau dalam bahasa indonesia disebut Teknologi Informasi dan Komunikasi (TIK) merupakan perangkat teknologi yang dimanfaatkan dalam pengelolaan data, penyusunan, penyimpanan dan manipulasi data melalui berbagai cara untuk memproses dan menyampaikan informasi yang berkualitas. Pada era modern ini TIK telah menjadi kebutuhan mendasar. Sebagian besar manusia telah menjadikan teknologi sebagai bagian dari kehidupannya. TIK telah banyak memberikan dampak positif di berbagai bidang kehidupan manusia, terutama di bidang informasi dan komunikasi. TIK mempermudah aktivitas komunikasi manusia, tanpa berfikir tentang jarak manusia bisa berkomunikasi dengan mudah, cepat dan lebih efisien. Penyebaran informasi pun demikian, dengan adanya TIK lebih mudah dan cepat untuk dilakukan.

Guna meningkatkan efektivitas dan efisiensi pembelajaran, diperlukan pengembangan suatu model pembelajaran yang inovatif dan kreatif agar proses pembelajaran tidak selalu terkesan membosankan, tidak menarik dan monoton yang dapat menghambat proses transfer ilmu. Oleh karena itu, peran media pembelajaran menjadi hal yang penting untuk diperhatikan. Internet dapat menjadi salah satu pilihan sebagai media pembelajaran yang cukup efektif mengingat internet merupakan alat komunikasi yang murah dan memungkinkan terjadinya interaksi antara dua orang atau lebih dimana saja dan kapan saja. Pembelajaran yang dilakukan melalui media internet dikenal sebagai e-learning. Karakteristik e-learning ialah pertama, memanfaatkan teknologi elektronik, dalam hal ini siswa dan guru dapat berkomunikasi dengan mudah tanpa dibatasi oleh hal-hal yang protokoler. Kedua, memanfaatkan keunggulan komputer. Ketiga, menggunakan bahan ajar yang bersifat mandiri, dapat 
diakses kapan dan dimana saja. Keempat, mampu me-record hasil kemajuan belajar. Edmodo merupakan salah satu media e-learning yang dapat diterapkan sebagai media pembelajaran. Edmodo tidak hanya mudah digunakan, namun juga menyediakan fitur-fitur yang mampu mendukung semua proses belajar beberapa diantaranya unggah materi dengan format bervariasi tidak hanya dalam ekstensi dokumen saja, pelaksanaan ujian yang realtime, pengumpulan tugas dengan batasan waktu yang bisa diatur, voting, saling berkiriman pesan, komentar, bahkan guru dapat memberikan penghargaan berupa lencana bagi siswa/i yang berprestasi. Tidak hanya itu, edmodo juga memungkinkan orang tua dapat mengawasi perkembangan kegiatan belajar mengajar anaknya.

E-learning dapat dimanfaatkan secara optimal jika tenaga pengajar memiliki kompetensi dan pemahaman terkait penggunaannya. Oleh karena itu, menyadari pentingnya hal tersebut mendorong SMP Negeri 29 Palembang untuk mengadakan pelatihan pembuatan e-learning sebagai media pembelajaran bagi siswa. Pelatihan tersebut telah dilaksanakan pada tanggal 5 Oktober 2017. Melalui kegiatan ini diharapkan para tenaga pengajar di lingkup SMP Negeri 29 Palembang memiliki kompetensi dan pemahaman untuk memanfaatkan e-learning sebagai media pembelajaran.

\subsection{Tujuan}

Tujuan yang hendak dicapai dari program ini adalah selain berguna untuk meningkatkan kompetensi tenaga pengajar, juga memberikan pengetahuan dan pelatihan sebagai penunjang kegiatan proses akademik khususnya pembuatan e-learning sebagai media pembelajaran bagi siswa.

\subsection{Manfaat}

Menyadari akan potensi dan permasalahan yang telah diuraikan pada latar belakang, maka perlu diadakan kegiatan yang dapat mengembangkan suatu suasana akademik pada lembaga-lembaga pendidikan seperti sekolah-sekolah dan sejenisnya serta mampu meningkatkan dan mengembangkan mutu dari proses belajar-mengajar.

\subsection{Bentuk kegiatan}

Beberapa kegiatan yang dilakukan selama kegiatan ini adalah pemaparan materi terkait $e$ learning yang kemudian dilanjutkan pada pelatihan pembuatan akun edmodo, pengenalan fitur-fitur edmodo dan bagaimana cara penggunaannya sebagai media pembelajaran siswa.

\section{METODE PELAKSANAAN PENGABDIAN}

\subsection{Persiapan pelaksanaan pengabdian}

Persiapan yang baik akan memudahkan dalam pelaksanaan Pelatihan Pembuatan e-learning sebagai Media Pembelajarab Siswa di SMP Negeri 29 Palembang serta menghindari permasalahan yang akan mungkin terjadi. Hal yang terkait dalam persiapan meliputi:

1) Melakukan diskusi dengan tim pelaksana tentang kegiatan pengabdiaan Masyarakat yang akan dilakukan serta materi yang akan disampaikan serta menetapkan jadwal kegiatan.

2) Pengajuan permohonan izin pada Dekan Fakultas Ilmu Komputer dan Kepala LP2MK Universitas Indo Global Mandiri tentang kegiatan pengabdian pada masyarakat yang akan dilakukan.

3) Dekan Fakultas Ilmu Komputer dan Kepala LP2MK Universitas Indo Global Mandiri menyetujui kegiatan tersebut dengan membuat surat izin pelaksanaan kegiatan pengabdian pada masyarakat.

4) Membuat Proposal kegiatan.

5) Mengajukan proposal pada Dekan Fakultas Ilmu Komputer yang telah ditandatangani ketua LPPM Universitas Indo Global Mandiri untuk melaksanakan kegiatan Pengabdian pada Masyarakat.

6) Mengajukan proposal pada Kepala Sekolah SMP Negeri 29 Palembang Sumatera Selatan.

7) Persiapan materi yang disampaikan Materi yang dipilih untuk disajikan adalah:

a. Pengenalan ICT

b. E-learning sebagai media pembelajaran

c. Edmodo sebagai salah satu e-learning

d. Langkah-langkah pembuatan dan penggunaan edmodo

8) Persiapan perlengkapan untuk presentasi

Komponen komputer beserta perlengkapan untuk digunakan dalam kegiatan pengabdian kepada masyarakat sebagai berikut: 
a. Komputer standar dengan sistem operasi windows

b. Kelengkapan lain seperti mouse, keyboard, printer dan projector.

c. Referensi dari beberapa media yang berbasis on-line.

9) Pelaksanaan Kegiatan.

10) Pembuatan Laporan Kegiatan

\subsection{Peserta}

Peserta Pelatihan Pembuatan e-learning sebagai Media Pembelajarab Siswa di SMP Negeri 29 Palembang diikuti oleh tenaga pengajar (guru) pada lingkungan SMP Negeri 29 Palembang.

\subsection{Waktu kegiatan dan materi}

Proses kegiatan dilaksanakan selama 1 hari pada hari Kamis, 5 Oktober 2017 pukul $10.00-12.30$ WIB. Kegiatan yang dilakukan selama pelatihan adalah :

a) Regitrasi peserta

b) Pembukaan.

c) Penyampaian materi dengan judul materi pelatihan pembuatan e-learning sebagai media Pembelajaran Siswa di SMP Negeri 29 Palembang. Jadwal pelaksanaan kegiatan secara rinci dapat dilihat pada Tabel 1 :

Tabel 1. Jadwal Pelaksanaan Kegiatan Pengabdian Kepada Masyarakat

\begin{tabular}{|c|c|c|}
\hline Pukul & Materi & Nara Sumber \\
\hline $08.00-08.30$ & Persiapan & \\
\hline $08.30-09.00$ & Registrasi Peserta & Mahasiswa \\
\hline $09.00-09.30$ & Pembukaan & Kepala Sekolah \\
\hline $09.30-10.00$ & $\begin{array}{l}\text { Pembukaan dan Perkenalan } \\
\text { dengan nara sumber }\end{array}$ & Tim Pelaksana \\
\hline \multirow{4}{*}{$10.00-11.00$} & \multirow{4}{*}{ Materi } & Dewi Sartika \\
\hline & & Husnawati \\
\hline & & Imelda Saluza \\
\hline & & Maya Amalia \\
\hline $11.00-12.30$ & $\begin{array}{l}\text { Praktek Pembuatan } e- \\
\text { learning edmodo }\end{array}$ & Tim Pelaksana \\
\hline
\end{tabular}

\section{HASIL DAN PEMBAHASAN}

Kegiatan Pengabdian Kepada Masyarakat "Pembuatan e-learning sebagai Media Pembelajarab Siswa di SMP Negeri 29 Palembang" bertujuan untuk membantu membangun suasana akademik lebih hidup dan menjadikan tenaga pengajar lebih kreatif dan berkompetensi untuk memanfaatkan $e$ learning sebagai media pembelajaran sehingga kegiatan belajar mengajar dapat dilakukan dimanapun dan kapanpun. Hasil kegiatan Pelatihan Pembuatan e-learning sebagai Media Pembelajaran Siswa di SMP Negeri 29 Palembang antara lain:

1) Membuka pemikiran tenaga pengajar agar mau memanfaatkan teknologi sebagai media pembelajaran

2) Membantu tenaga pengajar dalam membuat media belajar yang dapat dimanfaatkan guru dan siswa dimanapun dan kapanpun.

3) Membantu tenaga pengajar dalam mengembangkan media pembelajaran menggunakan e-learning edmodo.

4) Mengaplikasikan media pembelajaran yang telah dibuat untuk diterapkan dalam kegiatan belajar dan mengajar.

Pemahaman mengenai ICT serta manfaatnya dalam dunia pendidikan diharapkan mampu membuka pikiran SMP Negeri 29 Palembang untuk menerapkan penggunaan ICT dalam lingkungan 
sekolah sebagai media pembelajaran yang lebih efektif, efisien, atraktif dan menarik, sehingga proses pembelajaran menjadi lebih mudah, dapat dilakukan dimana saja dan kapan saja, serta mengurangi kejenuhan dalam belajar terutama pelajaran mengenai ilmu eksak yang selama ini menjadi momok. Pelatihan pembuatan e-learning sebagai media pembelajaran bagi siswa ini diharapkan dapat menjadi bekal bagi seluruh tenaga pengajar dilingkungan SMP Negeri 29 Palembang dalam meningkatkan keahlian mereka dalam membuat media pengajaran yang efektif dan efisien bagi siswa/i sehingga SMP Negeri 29 Palembang mampu terus meningkatkan kualitas, nilai tambah serta daya saingnya terhadap SMP - SMP Negeri lainnya di Palembang.

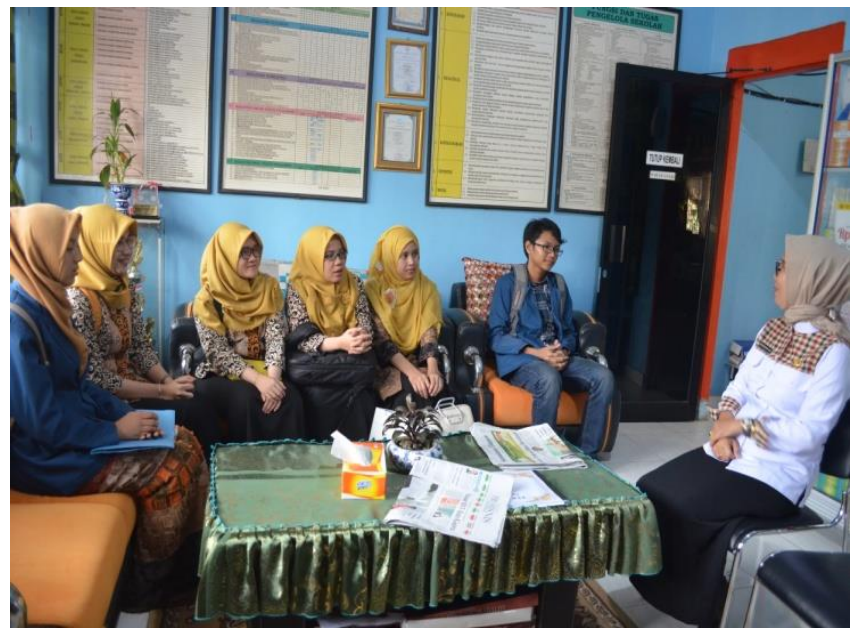

Gambar 1. Diskusi dengan Kepala Sekolah SMPN 29 Palembang

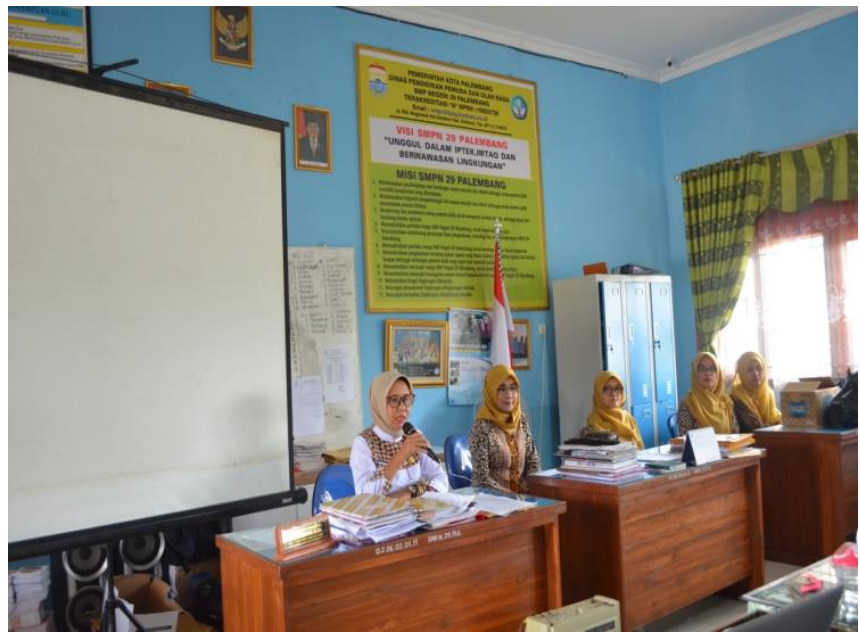

Gambar 2. Pembukaan oleh Kepala Sekolah SMPN 29 Palembang

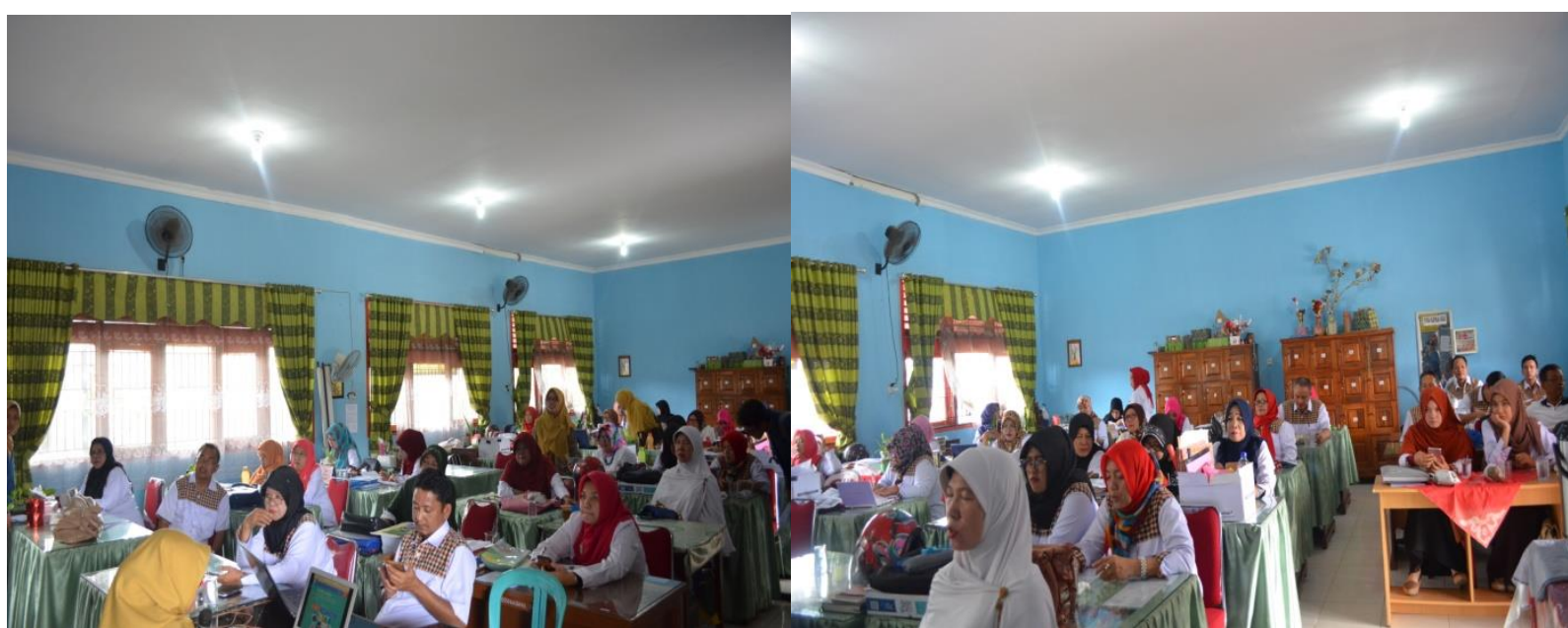

Gambar 3. Pelaksanaan Pelatihan Pembuatan e-learning 


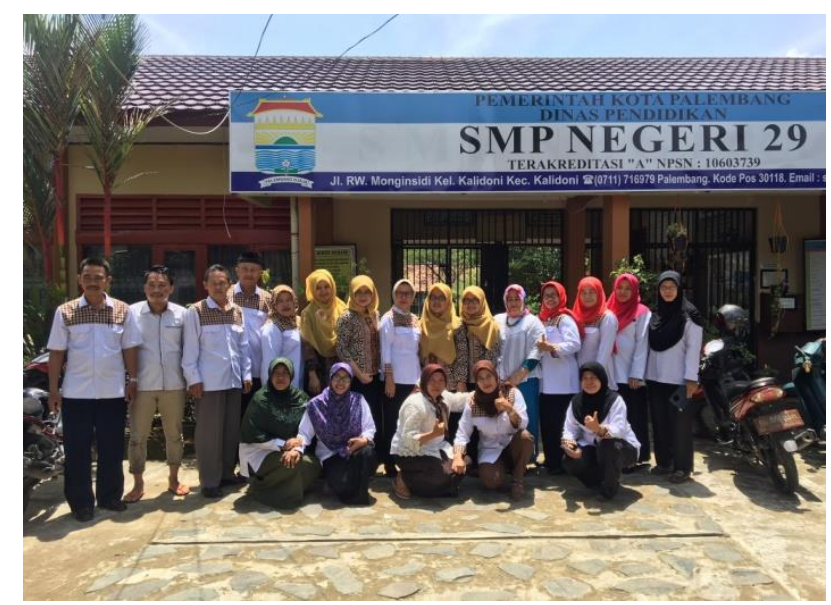

Gambar 4. Foto Bersama dengan Peserta Pelatihan

\section{KESIMPULAN}

Berdasarkan hasil pelaksanaan kegiatan pengabdian pada Masyarakat dapat disimpulkan sebagai berikut :

1) Kegiatan terlaksana sesuai dengan tujuan dan rencana.

2) Kegiatan ini mendapat sambutan dan antusias yang baik dari kepala sekolah maupun seluruh tenaga pengajar SMP Negeri 29 Palembang Sumatera Selatan.

3) Kegiatan ini dapat meningkatkan kemampuan para tenaga pengajar dalam membuat dan mengembangkan media belajar menggunakan e-learning

\section{UCAPAN TERIMA KASIH}

Segala puji dan syukur kami panjatkan kehadirat Alah SWT karena berkat rahmah dan karunia-Nya, rangkaian kegiatan pengabdian kepada masyarakat ini dapat terselesaikan. Pengabdian kepada masyarakat adalah bagian dari Tri Dharma Perguruan Tinggi bagi setiap dosen. Laporan akhir pengabdian kepada masyarakat ini disusun sebagai rangkuman dari seluruh rangkaian kegiatan pengabdian kepada masyarakat yang masih jauh dari kesempurnaan. Saran dan kritik yang membangun sangat diharapkan demi perbaikan dan sempurnanya laporan ini. Ucapan terima kasih kami sampaikan kepada semua pihak yang terkait, terutama kepada kepala Sekolah SMP Negeri 29 Palembang, yang mendukung, membantu dan mendoakan keberhasilan kegiatan pengabdian masyarakat ini, serta para tenaga pengajar SMP Neheri 29 yang telah antusias dalam menerima materi pelatihan yang diberikan. Semoga pelatihan yang telah diberikan dapat bermanfaat bagi tenaga pengajar serta siswa/i SMP Negeri 29 Palembang dalam proses belajar mengajar.

\section{DAFTAR PUSTAKA}

Muhson, A. 2010. Pengembangan Media Pembelajaran Berbasis Teknologi Informasi, J. Pendidik. Akunt. vol. VIII, no. 2. Indonesia

Agustina, M. 2013. Pemanfaatan E-Learning sebagai Media Pembelajaran, no. 12, pp. 8-12.

Hanum, N.S. 2013. Kefektifan e-learning sebagai media pembelajaran (studi evaluasi model pembelajaran 2-learning SMK Telkom Sandhy Putra Purwokerto),vol. 3, pp. 90-102.

Yazdi, D. J, M Matematika, and U. Tadulako. 2012. E-learning sebagai media pembelajaran. vol. 2, no. 1, pp. 143-152.

Setyono, E.Y and S. Dan. 2015. Pengaruh Penggunaan Media Jejaring Sosial Edmodo Terhadap Hasil Belajar Mahasiswa Pada Topik Pembuatan Kurva-S Menggunakan Microsoft Excel. J. Sos. dan Hum., vol. 5, no. 1, pp. 42-49.

Ainiyah, Z. 2015. Penggunaan Edmodo Sebagai Media Pembelajaran E-Learning Pada Mata Pelajaran Otomatisasi Perkantoran Di SMKN 1. Surabaya. 